\title{
Infiltração conjuntival como primeira manifestação de leucemia mielóide aguda - relato de caso
}

\author{
Conjunctival infiltration as first clinical manifestation of acute \\ myelogenous leukemia - a case report
}

\author{
Ciro Massaiuki Komagome ${ }^{(1)}$ \\ Luciene Barbosa de Sousa ${ }^{(2)}$ \\ Maria do Carmo Pinheiro ${ }^{(3)}$ \\ Moacyr Rigueiro ${ }^{(4)}$ \\ Isabel Cristina Proença Gil ${ }^{(5)}$ \\ Denise de Freitas ${ }^{(6)}$
}

\begin{tabular}{|c|}
\hline RESUMO \\
\hline $\begin{array}{l}\text { Os autores descrevem o caso de paciente portadora de leucemia } \\
\text { mielóide aguda que apresentou como primeira manifestação da } \\
\text { doença, infiltração leucêmica conjuntival. São feitas considerações a } \\
\text { respeito das manifestações sistêmicas e oftalmológicas e atualização } \\
\text { desta doença. }\end{array}$ \\
\hline
\end{tabular}

\section{INTRODUÇÃ̃O}

As leucemias são neoplasias derivadas de células hematopoéticas, que proliferam a princípio na medula óssea, antes de se disseminar para o sangue periférico, baço, linfonodos e por fim, outros tecidos ${ }^{1}$.

A classificação das leucemias baseia-se, em grande parte, na célula de origem (linfóide ou mielóide), bem como na velocidade de seu curso clínico (aguda ou crônica). A leucemia aguda caracteriza-se pela proliferação clonal de células hemapoéticas imaturas. De acordo com a linhagem, pode ser dividida em leucemia mielóide aguda (mieloblastos ou promielócitos) ou leucemia linfocítica aguda (linfoblastos) ${ }^{1}$.

As manifestações clínicas da leucemia mielóide aguda se caracterizam por quadro de anemia, palidez, fatigabilidade fácil e dispnéia aos pequenos esforços. O sangramento está relacionado ao quadro de trombocitopenia, podendo estar associado com aparecimento de petéquias e equimoses. A infecção é uma complicação praticamente universal da leucemia aguda e é inversamente proporcional ao número de neutrófilos circulantes ${ }^{1}$.

Pode-se verificar o desenvolvimento de massas de células leucêmicas em tecidos moles em qualquer localização, sendo que algumas vezes a leucemia extramedular com acometimento ocular pode preceder o comprometimento detectável da medula óssea ${ }^{3}$.

$\mathrm{O}$ acometimento de tecidos oculares é raro tendo a retina e coróide como sítios mais comuns. Alterações retinianas ocorrem em 30\% a 90\% dos casos de leucemia ${ }^{3,4}$. Dilatações e aumento de tortuosidade dos vasos e hemorragias retinianas são os achados mais comuns. Porém, pode-se observar exsudatos algodonosos e manchas acinzentadas indicando infiltração leucêmica ${ }^{3}$.

A coróide é um dos tecidos oculares mais envolvidos por infiltração leucêmica em estudos histopatológicos, variando de $65 \%$ a $85 \%$. Os achados mais comuns são aumento da espessura, hiperplasia e hipertrofia dos tecidos uveais ${ }^{3}$. 
A infiltração leucêmica da íris e segmento anterior do olho é mais rara, porém já foram descritos casos que simulavam quadros de uveítes, com formação de pseudohipópio provenientes das células tumorais ${ }^{6}$. Outros achados que podem ser observados são heterocromia de íris e glaucoma agudo ${ }^{3,10}$.

A órbita pode estar envolvida em cerca de $8 \%$ dos casos de leucemia mielóide aguda, mais comumente em quadros agudos. O quadro clínico característico é de proptose, edema palpebral e quemose ${ }^{5,7}$. Massa orbital de células da linhagem mieloblástica eram conhecidas como cloromas ou sarcomas granulocíticos devido à coloração esverdeada decorrente da reação da enzima mieloperoxidase ${ }^{5}$.

Acometimento da córnea é muito raro devido à característica avascular do tecido corneano ${ }^{3}$.

O objetivo do trabalho é apresentar e discutir as manifestações clínicas num caso raro de infiltração leucêmica em conjuntiva.

\section{RELATO DO CASO}

E.B.S., 20 anos, do sexo feminino, natural de Goiás e procedente de São Paulo há 10 anos. Procurou nosso serviço, com queixa de olhos inchados e saída de secreção há 4 meses. Procurou outros serviços de oftalmologia tendo sido tratada com colírio de ciprofloxacina associado a dexametasona, três vezes ao dia por três semanas, sem melhora do quadro. Referia febre diária, adinamia e perda ponderal de $7 \mathrm{Kg}$, nesse período. Há 1 mês referia epistaxe e hematomas espontâneos.

No exame físico geral apresentava-se em regular estado geral e descorada ++ .

À palpação, o fígado apresentava-se a $2 \mathrm{~cm}$ do rebordo costal direito.

Ao exame oftalmológico, apresentava acuidade visual sem correção de 0,5 no olho direito e 0,4 no olho esquerdo.

À ectoscopia, apresentava em ambos os olhos edema palpebral +++ , hiperemia +++ e quemose conjuntival.

Ao exame biomicroscópico do segmento anterior, observava-se em ambos, os olhos a presença de hiperemia e quemose conjuntival, micropapilas e folículos esparsos na conjuntiva tarsal, úlceras conjuntivais recobertas por material fibrinóide e cicatrizes adjacentes associadas à saída de secreção mucóide esbranquiçada e membranas (Figura 1). Na córnea observava-se ceratite punctata em ambos os olhos.

A medida da pressão ocular era $12 \mathrm{mmHg}$ em ambos os olhos, motilidade ocular extrínseca e fundoscopia não apresentando alterações.

Para esclarecimento diagnóstico, foram solicitados os seguintes exames: hemograma, VDRL, FTA-Abs, PPD, urina I, Rx de tórax e de seios da face, provas reumatológicas (VHS, FAN, pANCA, células LE), colheita de material da conjuntiva tarsal para citologia e cultura e biópsia incisional das lesões conjuntivais.

Após 05 dias de evolução, a paciente retornou com quadro inalterado. Os resultados dos exames foram todos normais, com exceção do hemograma que revelou anemia, plaquetopenia e leucocitose (blastos 35\%). O exame anátomo-patológico da lesão conjuntival revelou presença de infiltrado difuso do córion por células atípicas de citoplasma eosinofílico e

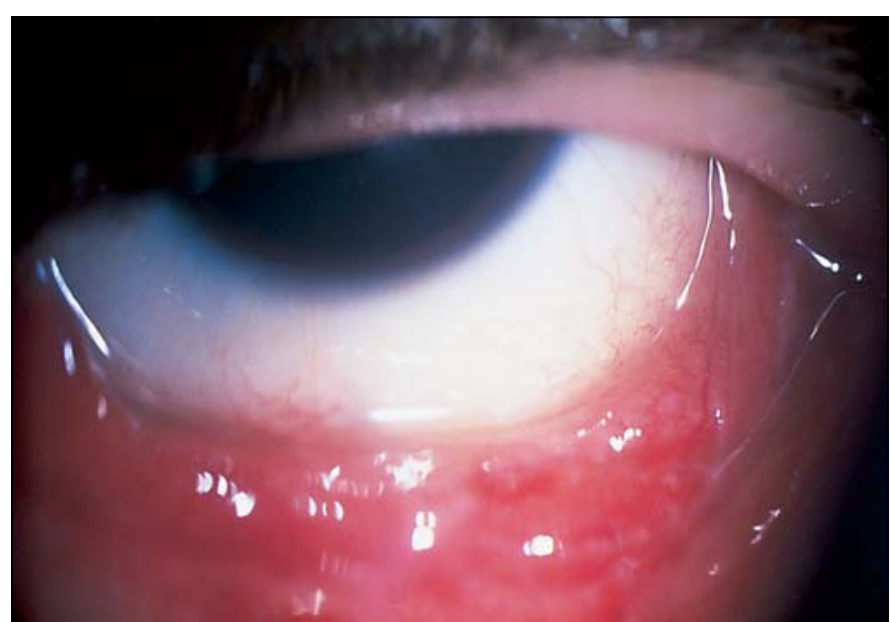

Fig. 1 - Infiltração leucêmica simulando lesões granulomatosas em conjuntiva tarsal.

granuloso, com presença de figuras de mitose sugestivas de origem mielóide granulocítica (Figura 2). O exame imunohistoquímico pelo método da strepto-avidina-biotina-complexo peroxidase mostrou positividade para antígeno leucocitário comum e lisozima.

Frente ao quadro, a paciente foi internada e submetida à tomografia computadorizada de crânio e órbita. Repetição do hemograma mostrou $7,0 \mathrm{~g} / \mathrm{dl}$ hemoglobina, hematócrito de $21 \%, 113000 / \mathrm{mm}^{3}$ plaquetas, $9700 \mathrm{~mm}^{3}(1-38-2-0-13-0)$ glóbulos brancos e presença de $46 \%$ de células blásticas (Figura 3).

O mielograma com imunofenotipagem revelou presença de medula óssea hipercelular, com 44,5\% de blastos mielóides (com bastonetes de Auer) e marcadores mielóides positivos e linfóides negativos. Foi feito o diagnóstico de leucemia mielóide aguda, subtipo M2 (mieloblástica aguda com diferenciação) (Figura 4).

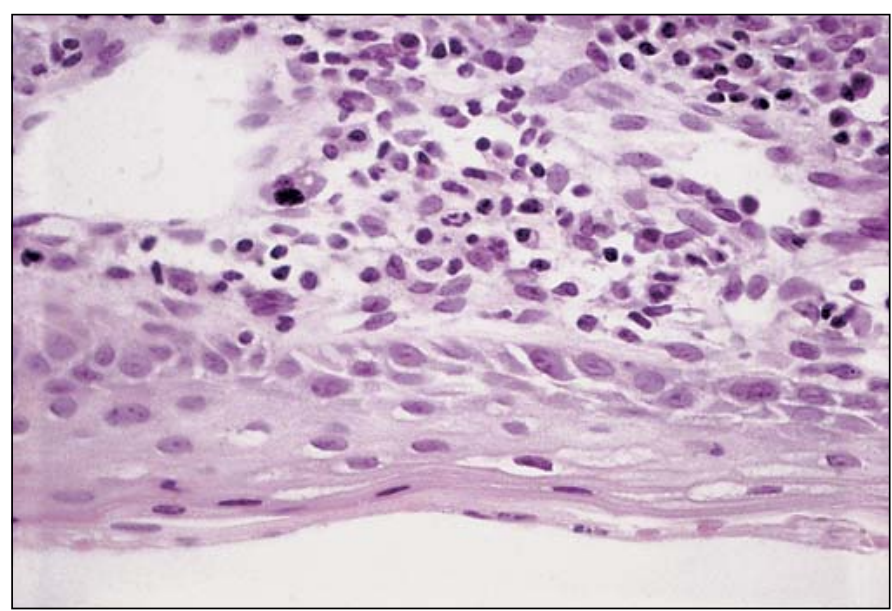

Fig. 2 - Exame anátomo-patológico de biópsia conjuntival. Observa-se presença de células atípicas de citoplasma eosinofílico, granuloso e figuras de mitose. 


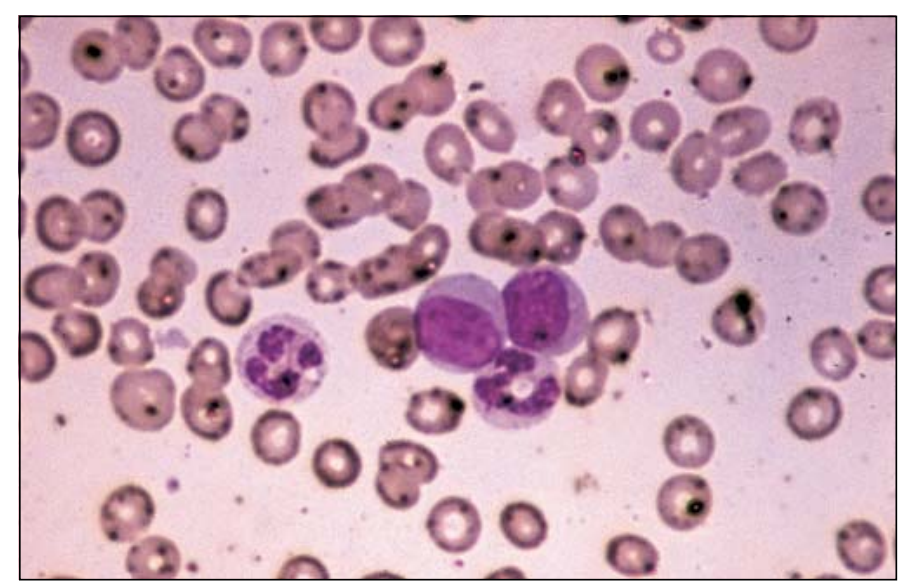

Fig. 3 - HE de sangue periférico. Observa-se células blásticas.

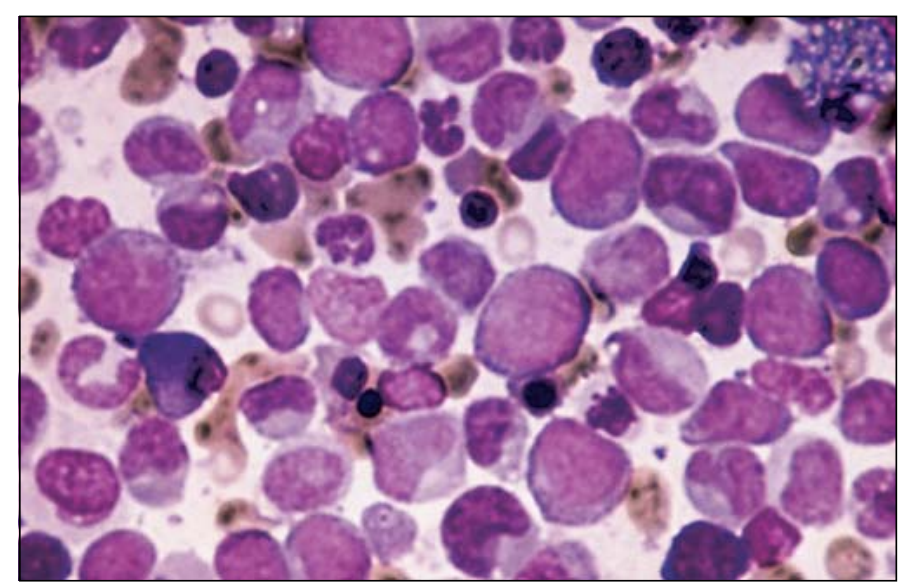

Fig. 4 - Mielograma. Observa-se medula óssea hipercelular com inúmeros blastos mielóides.

A paciente foi submetida a tratamento quimioterápico com daunorubicina e cytarabina levando a regressão progressiva do quadro ocular, posteriormente submetida ao transplante de medula óssea.

\section{DISCUSSÃO}

A leucemia envolvendo os tecidos oculares é rara, embora possa ser a primeira manifestação extramedular da doença e simular diversas outras alterações oculares ${ }^{1}$.

A infiltração leucêmica conjuntival como primeira e única manifestação de um quadro de leucemia mielóide aguda foi descrita apenas uma vez na literatura médica ${ }^{2}$. Geralmente envolve os tecidos oculares mais tardiamente sendo a retina, órbita, nervo óptico e trato uveal os locais mais acometidos ${ }^{3-5}$.

$\mathrm{O}$ envolvimento conjuntival é mais freqüente nos pacientes com leucemias linfocíticas. Em estudo retrospectivo, foi encon- trado 4\% (14/384) de algum grau de infiltração leucêmica, porém nenhum dos casos revistos eram de leucemias de linhagem mieloblástica como o caso descrito $2,3,8$.

Em nosso caso, o diagnóstico foi confirmado pela biópsia conjuntival, porém este método mostrou baixa positividade nos trabalhos em que havia suspeita de infiltração leucêmica da conjuntiva.

A paciente apresentava um quadro de leucemia mielóide aguda subtipo M2 (LMA-M2). O prognóstico é satisfatório em adultos jovens, quando associado à hepatoesplenomegalia e infiltração de tecidos moles, geralmente relacionado às alterações cromossômicas, no caso translocação $t(8,21)^{1}$.

No caso relatado, o acometimento foi extraocular com infiltração da conjuntiva tarsal, confirmada pela biópsia incisional. A paciente não apresentava alterações tomográficas, restringindo-se a infiltração apenas ao tecido conjuntival.

Por fim, ressalta-se a importância de se realizar uma propedêutica geral e bem direcionada em casos de alterações oculares atípicas, que podem ser a primeira manifestação de doenças sistêmicas graves.

\section{SUMMARY}

The authors present a case of acute myelogenous leukemia whose first symptom was infiltration of the conjunctiva. The clinical and ophthalmologic characteristics are discussed and reviewed.

Keywords: Leukemia, myelocytic; Conjunctiva; Chloroma; Granulocytic sarcoma.

\section{REFERÊNCIAS BIBLIOGRÁFICAS}

1. Scheinberg DA, Golde DW. The leukemias, Harrison's. Principles of Internal Medicine, $13^{\text {th }}$ ed, McGraw-Hill, 1994, cap 310.

2. Lee DA, Su WPD. Acute myelomonocytic leukemia cutis presenting as a conjunctival lesion. Internat J Dermatology 1985;24:369.

3. Kincaid MC, Green WR. Ocular and orbital involvement in leukemia. Surv Ophthalmol 1983;27(4):211.

4. Karesh JW, Goldman EJ, Reck K, Kelman SE, Lee EJ, Schiffer CA. A prospective ophthalmic evaluation of patients with acute myeloid leukemia: correlation of ocular and hematologic findings. J Clin Oncol 1989;7(10):1528.

5. Zimmerman LE, Font RL. Ophthalmologic manifestations of granulocytic sarcoma. Am J Ophthalmol 1975;80(6):975.

6. Ayliffe W, Foster CS, Marcoux P, Upton M, Legmann A. Relapsing acute myeloid leukemia manifesting as hypopyon uveitis. Am J Ophthalmol 1995;119(3):361.

7. Ford JG, Yeatts RP, Hartz JW, Chauvenet A. Granulocytic sarcoma of the eyelid as a presenting sign of leukemia. J Ped Ophthalmol Strabismus 1993;30:386.

8. Mansour AM, Traboulsi EI, Frangieh GT, Jarudi N. Caruncular involvement in myelomonocytic leukemia: a case report. Med Ped Oncol 1985;13:46.

9. Curto ML, Zingone A, Acquaviva A, Bagnulo S, Zanesco L. Med Ped Oncol 1989; $17: 134$.

10. Katz SE, Wade K, Anderson DP, Rootman J. Anterior segment recurrence of acute myelogenous leukemia: treatment with subconjuntival injections of methotrexate and triancinolone acetonide. Can J Ophthalmol 1997;32(4):265. 